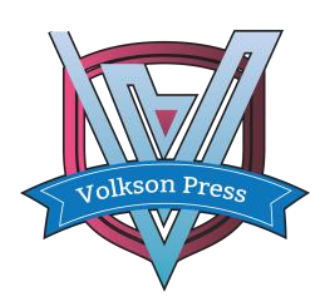

Contents List available at VOLKSON PRESS

Economics \& Management Innovations(EMI)

DOI : http://doi.org/10.26480/icemi.01.2017.27.29



\title{
Adopting Legal Means to Better Handle Stampede Accident by Massive Crowd
}

\author{
Shan Jiadi ${ }^{1}$, Shen Laijin ${ }^{2}$ \\ ${ }^{1}$ School of Arts and Law, Wuhan University of Technology, Wuhan, P.R.China, 430070 \\ ${ }^{2}$ School of Arts and Law, Wuhan University of Technology, Wuhan, P.R.China, 430070 \\ E-mail: 63000978@qq.com,30198211@qq.com
}

This is an open access article distributed under the Creative Commons Attribution License, which permits unrestricted use, distribution, and reproduction in any medium, provided the original work is properly cited.

\section{ARTICLE DETAILS}

\section{Article History:}

\section{Received 02 october 2017}

Accepted 06 october 2017

Available online 11 october 2017

\section{Keywords:}

Stampede Accident; Preventive

Law; Special Legislation;

Enforcing Law in Advance;

Responsibility and Relief; Legal

Education and Propaganda on Safety.

\section{ABSTRACT}

Stampede accident, a sort of large-scale man-made accidents, has frequency been reported in recent years, calling for urgent attention to be dealt with. A typical stampede accident has such prominent features: its odds are low but it can take place in a sudden and result in a serious consequence. So far our government has already adopted certain measures to both prevent and handle stampede accident, but they are not working well as those measures are designed not to deter stampede accident from happening in the origin place. After a deep reflection on the failure of previous measures and on the basis of thousands of documents and thesis concerning stampede accident, an useful conclusion is made that only by legal means will stampede accident be successfully handled. To support the above finding, the necessity of adopting legal means must be analyzed and the legal frameworks which consist of legal means must be introduced. It then turns out that four legal frameworks must be adopted to better handle stampede accident. Those legal frameworks include: (a) enacting special laws which regulate on public activities of massive crowd;

(b) taking preventive legal measures on the part of administrative agencies concerned; (c) establishing and developing ex post regimes both of responsibility taking and relief seeking; (d) enhancing ordinary people's security education and propaganda on stampedeaccident.

\section{Introduction}

Stampede accident is a sort of accident which often take place in circumstance of massive crowd and often result from the losing control of on-site order. Usually, it takes the form of congestion and chaos and ends up with plenty of injuries, suffocation and deaths. Nowadays there are frequently public activities held at places like school, stadium, shopping mall, places for public gathering, entertain spot and religious district and so on. As a result, the odds of stampede accident rise sharply and the very accident is becoming one of the most serious public accidents. In 1990, there was an unprecedented stampede accident in Mekka, which resulted in 1,426 death. In 2015, again in Mekka, another stampede accident happened and it took 717 lives. The case in China is serious, too. On December 31th, 2014, 36 people were died and 49 people got injured in a stampede accident happening at the Bund, Shanghai. In the year of 2014, KunMing MingTong school witnessed another stampede accident, with 6 students losing their lives. On February 27th, the same nightmare took place at QinJi school, LaoHeKou city, HuBei province, with 11students injured and 4 students died. In the year of 2004, the light campaign for greeting spring in MiYun ended up with 37 death and 37 injures as a result of stampede accident. The uncontrolled stampede accidents has a terrible implications for it does harm to both the lives of ordinary people and the government credibility. The reasons why these accidents happen can be sought in various aspects, including management, massive crows, background settings and public quality, among which the aspect of management should be the core reason.

All the above mentioned stampede accidents tend to happen at medium or large cities with dense population. Other characteristics of stampede accident include: its odds are low but it can take place in a sudden and result in a serious consequence of both deaths and injuries; the causes are various; and it's hard to control.
In view that our country has suffered from the pain of large-scale stampede accidents, Chinese government has introduced all kinds of measures to both prevent and deal with stampede accident. For example, administrative agencies concerned have adopted plenty of emergency measures and they have at the same time been devoted to security propaganda. It's true that those measures have led to the accumulation of experiences but they are not working well. To understand the patterns of stampede accident comprehensively and find out the reasons for the failure of the aforementioned measures, there are government work conferences and academic researches focusing on both the proposed measures and relevant theories. Based on those studies and bearing in mind that those so called multiple approaches with excellent working scheme have not achieved the desired effect of preventing stampede accident, the author of this paper concludes that for city security management it is not experience but science as well as legal regime which is in conformity with science that counts.

\section{The Necessity of Adopting Legal Means}

The fundamental reason for the repeated stampede accident is the want of legal means and emergency plans. Indeed there exist some regulations in force governing stampede accident but they are too abstract to enforce or execute. Administrative agencies concerned always find themselves in a dilemma where there are actually no laws to follow. So in fact a better description of the obstacle we encounter may not be the lack of legal means or rules. There are indeed "rules or regulations concerning stampede accident". But the true reality, which should be deemed as the key reason for repeated stampede accident, is that there is no enforceable legal frameworks to guide our government. As a result, the administration of public activities is always in chaos. For example, there is no advance estimate about the flows of people, no assessment done on possible risks, no in-time guidance or arrangement when stampede accident happens. Even the hospital institutions often can not receive the message of accident in the first place and thus are unable to 
go to the spot for rescue immediately.

While arguing to adapt legal means to handle stampede accident, it is necessary to make clear the meaning of legal means. When it comes to legal means in China, there is always two different interpretations: to rule by law or to rule by using rules of laws. These two interpretations may look like the same, but they actually are different. The former emphasizes legal means with the comparison of other kinds of means such as government policy, morality or despotic willing of leaders. The latter, at the same time, means a much more detailed rules of laws. To rule by law can be also called nomocracy, which encompasses such an overwhelming principle that the law within a country is of super authority and a state can only be governed on the basis of law rather than preferences of official leaders. Meanwhile, to rule by using rules of laws often consists of various legal schemes contained in laws or regulation. It is a concept more enforceable.

Based on above analysis, this paper tries to figure out the relationship between legal means and stampede accidents. It is strongly suggested that a special law regulating stampede accident be enacted. Because a special law is always the first choice to be used to rule on something of special character. This is further manifested by both the failure of existing general law and the special character of stampede accident. On the other hand, while acknowledging the toughness of introducing more enforceable rules of law, the author proposes some legal frameworks hoping it will be helpful when handling stampede accident.

\section{Four Legal Frameworks for Handling Stampede Accident}

Enhancing legal frameworks of stampede accidents means establishing a guidance or instruction to the relevant people concerned. In particular, these frameworks serve as a basis for administrative agencies who are actually the most important element in enforcing the said frameworks. This author agrees with the old wisdom that an accident is better solved if it is prevented or handled at an early stage. Thus what matters most is to deter stampede accidents from happening in the original place.

\subsection{Enacting a special law on stampede accident}

Firstly, enact special laws or regulations on stampede accident. There is a law in force in China called Emergency Response Law of the People's Republic of China. And there are also some regulations or normative documents of lower hierarchy which aim at enforcing the Emergency Response Law. But it is not enough. If you closely look at those mentioned documents, you will find that the provisions provided for do not mention stampede accident, although there indeed exist provisions concerning social massive accident. As said earlier in this paper, stampede accident owes some unique characters that deserve special legislature. So we need make a distinction between stampede accident and other social massive accident.

There are a few thesis in academic regarding stampede accident. But nearly all those thesis focus on themes like the reasons for stampede accident, the emergency measures used to handle stampede accident, the reliefs available after stampede accident and so on. Few has shed light on the issue in the perspective of law. Now that the existing systems of stampede settlement are proved to be not working, it is time for a special law to show up.

\section{2}

\section{Making preventive legal measures a priority}

The relevant administrative agencies who are responsible for handling stampede accident need make measures of preventive nature a priority. Those preventive measures should also be legal in nature, too. Focusing on preventive legal measures also calls for strict appliance, which, in the eyes of this author, is the core of preventing stampede accident. Strict appliance to preventive legal measures is in particular important when it comes to big cities which are often the places for gatherings of massive crowd, festival events, concerts, sporting games and other economic activities of large scale. However, strict appliance to preventive legal measures is by no means an easy work since it often involves checking closely on every step of a particular event. This may also make it a costing job effort to do. But compared to the costs incurred during a stampede accident, the expenses of preventive legal measure can be cheap in some sense. After all, stampede accident always means lives in danger, which can not be bought back by money. What is more, the people of China has witnessed plenty of stampede accidents during which the relevant administrative agencies often respond with ex post emergency measures. And it turns out that the often showing-up-late emergency measures do not work well alone. This further manifests the necessity of preventive legal measures. The relevant government departments must keep in mind that while the odds of stampede accident are low both the country and people can not tolerate a single stampede accident as it often result in huge losses. Preventive legal measures can be taken in various aspects. Now the preventive legal measures make a profound meaning in these circumstance. But it is impossible to list out all the circumstances in which a special preventive legal measure should be introduced. In this sense, focusing on preventive legal measures is more like a principle of law.

\subsection{Establish a complete accountability mechanism}

The system of administrative accountability embodies the principle of the unity of power and responsibility, the coexistence of power and responsibility, the use of responsibility to restrain the power, which remedies the defect that the traditional politics ignored the accountability of the responsibility of political and leadership, and improves the process of exercising power responsibility system for the modern government. It also sternly strikes and puts an end to corruption in the process of administrative and law enforcement, strengthens the ability of law enforcement workers to resist corruption and remedies the bad style of government and civil servants' malfeasance. If the administrative accountability mechanism fail to maintain fairness and justice, the process of Chinese judicial reform will be seriously hampered. The demand of the public for the administrative accountability should be translated into the internal motivation for functional departments to think about that how to promote the relevant accountability and improve the accountability mechanisms.

\subsection{Enhancing ordinary people's security education and propaganda on stampede accident}

Safety education includes security knowledge education and skills education, both of which are mutually reinforcing. It can be said that bearing in mind a good sense of security all the time can maximumly reduce the stampede situation in public places. Then a good social public security environment will be formed. Safety consciousness education should teach the public to judge surrounding environment correctly and cultivate a scientific sense of security; safety knowledge and skill education is to spread various safety knowledge and teach the public the full security knowledge and self-help measures. So people can confronted with danger and take the right measures to protect themselves and others, the promotional forms can be media column interviews, newspaper columns, community knowledge publicity and campus propaganda. In order to carry out safety education in time, the radio, micro-letter, microblogging, brochures and other channels can be used to preach security knowledge, also can organize related personnel to carry out the plan exercises, in advance strictly risk identification, assessment and disposition, there are good methods to eliminate the risk source in the bud.

\section{Conclusion}

The large-scale stampede has been the focus of the society at present, if we can not adopt the effective measures, the worst result is that a large number of people will be hurt by crowded, suffocated or injured in the accident. Every time the stampede happened, the government and other communities have adopted a variety of ways such as legislation, accountability, safety education and other measures to improve the situation, but it's not very effective. The reason that the stampede happened frequently is the shortcomings of law enforcement and nonfeasance of the government. It is impossible to solve the problem of system just by calling to raise the public safety consciousness after researching the study of stampede. How to reorganize the supervising subject and standardize the regulator is the first question. Therefore, only applying the rule of law by mandatory measures could completely remedy the old mode, it is also the fundamental strategy to promote the rule of law and accelerate the realization of China's law.

\section{References}

[1] Kou Liping. Reason Analysis and Prevention Research of Stampede [J]. Journal of Chinese People's Public Security University,2005,(4)(In Chinese)

[2] Yuan Qianli. Crowded Stampede Reason and Emergency Disposal to Explore the Reflection of Shanghai Bund Orientation Stampede [J]. China Emergency Rescue,2015,(2)(In Chinese)

[3] Jiang Bixin, Wang Hongxia. Relying on the Rule of Law in Social Governance[J].Law and Social Development,2014,(4)(In Chinese) 
[4] Uriel Rosenthal, Michael T. Charles and Paul T. Hart. Coping with Crises: The Management of Disasters, Riots and Terrorism. Springfield, III. Charles C. Thomas Publisher Ltd.1989:10

[5] See the Advisory Opinion of the Inter-American Court of Human Rights on Habeas Corpus in Emergency Situations, No.OC 8/87,9 Human Rights Law Journal 94.1988

[6]David Maxfield, Workplace Safety is the Leading Edge of a Culture of Accountability. EHS Today, Vo1.3, No.6,2010

[7] Joseph Grenny, David Maxfield, When Candor and Accountability are Missing, Five Crucial Conversations Corrupt Safety. Industrial Safety and Hygiene News, Vo1.44, No.10, 2010

[8] Accountability Based Safety: A New Solution to an Old Problem. http://www.pdfio.com/k-718277.htm1(2011-09-0S). 